Journal

of Geography,

Politics and Society

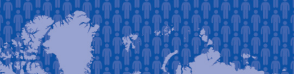

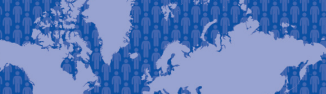

.

(1)

\section{Journal of Geography, Politics and Society}

$2017,7(3), 36-40$

DOI 10.4467/24512249JG.17.025.7181

\title{
ENVIRONMENTAL PROBLEMS AND ENVIRONMENTAL POLITICS: AN EXAMINATION OF THE CONTEXT OF THE EU AND TURKEY RELATIONS
}

\author{
Bekir Parlak (1), Ýsmail Enes Parlak (2) \\ (1) Department of Political Science and Public Administration, Faculty of Economics and Administrative Sciences, Uludag University, Görükle Campus, 16059 \\ Nilüfer, Bursa, Turkey, \\ e-mail: bparlak21@gmail.com (corresponding author) \\ (2) Industrial Engineering Graduate Student, Uludag University, Görükle Campus, 16059 Nilüfer, Bursa, Turkey, \\ e-mail: ensparlak@gmail.com
}

\section{Citation}

Parlak B., Parlak Ý. E., 2017, Environmental problems and environmental politics: an examination of the context of the EU and Turkey relations, Journal of Geography, Politics and Society, 7(3), 36-40.

\begin{abstract}
Information and communication technologies have been one of these main instruments in the implementation of EU environmental policies. In this respect, EU poses a concrete, influential and important model bearing a potential to generate policies, norms, values and standards on the subject of environment as it does in many other issues. Depending on this suggestion, in this study, we aim to analyze and assess the Turkish and EU policies regarding the role of information and communication technologies in the creation of environmental information, its distribution and public access to environmental information sources. In this regard, EU's policies and technology-based initiatives have importance to a great extent in this period of serious debates in relation Turkey's membership talks with the Union. Furthermore, Turkey, by virtue of her geopolitics and geostrategic position in the region as well, stands on the center of regional environmental problems due to its industrial development potential and its crossroads location in the intersection of Black Sea and the Mediterranean among the important energy and transportation routes. Therefore, potential of access to environmental information renders itself vital to handle the ecological problems of the region. The paper is targeting to forecast and analyze these potential and possible future developments from the perspective of Turkish and EU affairs.
\end{abstract}

\section{Key words}

environmental problems, environmental policies, environmental information, national geographic level, Turkish case, European Union.

\section{Introduction}

In the years to come, environmental problems influenced the whole global society without respect to the parties that initiated environmental problems and they have become sensitive items on agendas of developed, underdeveloped, northern and southern hemisphere nations and capitalist and socialist countries. As the issue has become more and more alarming and understood globally, the environmental agenda has transformed itself to a field in which every relevant global party pursued common remedies and other solutions to the problem. By virtue of its cumulative characteristic, environmental 
problems are related to the parameters of most economic, social, cultural and political and administrative problems.

On the other hand, the structures and understandings arising from industrialization and urbanization have brought about a wide spectrum of problems beyond ideological nature. Among these, environmental issue has rendered itself to the most important and the most global item on the list. Parallel to its global characteristic, the issue in question has been awaiting global responses. The international and supranational characteristics of the problem have also necessitated the cooperation between global parties involved.

\section{Environmental problems and environmental politics in the national geographic level}

The events such as growth of the population, fast and unbalanced urbanization, and industrialization and over consumption together with the economical aspects lead towards the expansion of environmental problems. The negative impacts originating in this connection, due to an advantageous position in the production quantity by the pollution creating monopoles have led to environmental problems with a focus of discussion at local, regional and international level. Today the environmental topics are bringing different countries to a very complex reciprocal dependence on each other. The danger of extinct species in the environment compels nations to come to a mutual understanding on a global basis.

The concept of trans boundary pollution also transforms environment to an international issue rather than being solely national, thus pressing for regional and universal cooperation (Ökmen, 2003). For Example, Climate change is a global environmental problem that needs global cooperation for its solution. Several factors have been identified to make international cooperation more likely: greater scientific consensus; increased public concern; burden sharing between nations; short term political benefits; and the existence of previous, related multilateral agreements (Grundmann, 2007).

\section{Environmental problems, environmental politics and environmental information}

All efforts to protect and solve the environmental problems are a part of environmental politics. However, measures taken by the governments for the future development and protection of natural and created environments can be termed as environmental politics. Environmental politics in the sense of searching for solutions of concrete negative exposures beyond the observational trends, reactions and ideological speeches, takes different shapes in each country according to its characteristics but at almost all places understanding on some characteristics of environmental politics are met with. A creation of healthy environments for humans, protection and development of community environmental values, and sharing of the necessary load of environmental politics applications mean an adaptation to the principals of public justice (What is Turkey's..., 1987).

Environmental performance assessments servea diverse group of users, including scientists, technicians, policymakers, the media, and the general public. This puts different demands on the way the results are prepared and disseminated (Srebotnjak, 2007). Espacially the media hold an important position in influencing public opinion on these matters. The framing of issues is particularly important. It has been suggested that there is an issue attention cycle but that the media's influence in the climate case is secondary, 'reinforcing the perceptions of primary definers in the politics of global warming: scientists, states and corporations (Grundmann, 2007).

\section{The environmental politics of European Union}

One of the most important components both during the formation as well as enforcement of the EU environmental politics under question has been the 'Environmental Information'. A fast development in the information technology for procuring data and analysis techniques has proved of great help to ecology and environmental science (Williams et al., 2006). Knowledge and information technologies are capable of producing potential positive or negative effects on every step of sustainability (Hilty, 2006).

Because a need for functioning of the environmental politics, parallel to the globalization of environmental problems, is to a great extent dependent on the establishment and management of a good information infrastructure. In this sense, success of the application of environmental politics by the Union is closely related to the effective use of scientific technology and diffusion of information webs that will be created within this framework. One of the foundations occupying the frontline in the case of sustainable development in the Union, particularly during the period following Maastricht, is "European Environment Agency". 
In order to provide healthy and comparable information to the Union and the member states on the position of environment, the EEA; established in 1990 and put into force in 1993; has undertaken the function of providing centrally oriented sustainable development strategy during the periods of developing politics towards environmental protection (Bosch, 2002).

The aim of the agency was to help EU and member states in the improvement of environment, integration of problems related to the environment into economical politics and decision making on the progress towards sustainable development (Who is it?..., 2005). Among the working fields of agency are procurement and analysis of environmental information, coordination of EIONET and an information system, provide services to the European Commission, member countries of EEA, international organizations, conventions and agreements, provide suggestions related to the politics, and other topics related to this on a broader scale. The strategy of EEA for 2004-2008 is the third perennial working program prepared according to the outline mentioned in the establishment format of the Agency. It has been accepted in the meeting held on 25 November, 2003 by the EEA governing body and is on the same lines as sixth Action Program (EEA Signs..., 2004).

\section{Environmental policies of the Turkey in the perspective European Union}

The interest environmental policies regarding the protection of environment and formation of early environmental policies took a start in the mid-70s and accelerated throughout the 1980s. The idea of environmental protection and need for environmental policies materialized for the very first time in the United Nations Conference held in 1972 that also played important role in the making and formation of EU environmental policies. Eventually, it was stated that the environmental protection be asserted into the seventh-five-year-developmental program for the first time and actions and arrangements that would not curb the economic growth be taken immediately.

Henceforth, the environmental policy planning studies were initiated with this plan followed by the 1983 Environmental Legislation prepared in the spirit of 1982 Constitution, an important step in the process (What is Turkey's..., 1987). In particular, global and regional developments were emphasized in line with the stress laid upon increasingly important regional cooperation in the seventh-five-year-developmental program. In this framework institutions such as EU, NAFTA and Pacific Region cooperation gained importance and a tri-polar structure began to emerge. Parallel to these developments, these institutions became influential with their international norms and rules with sanctioning power. In this regard, it became impossible for nations to form effective policies in isolation with these institutions. It will be useful to open up a little more the relations on the environmental politics between EEA and Turkey as one of the topics in the National Programme, because the steps taken in this connection during the EU adaptation period and efforts spent have a special importance.

Turkey applied for membership to the EEA in June, 1999; the discussions were started by the EU commission with a representation from Turkey during the meeting held on 27 March, 2000 at Brussels. The topic under question has been taken into consideration in the meeting held on 17-18 May, 2000 with the authorities of Environmental General Directorate of EU Commission visiting Turkey during the renegotiations on "Participation Strategy" towards Turkey's participation in the programmers and membership in EEA.

In this meeting it has been openly stated by the EU Commission authorities that EEA is the first EU organization opening the doors towards the full membership of Turkey in EU. In the meeting of "EU and Standing Member Countries Ministers for Environment" a participation agreement was signed between "Turkey and EU on EEA and European Information and Observation Net" on 9 October, 2000 at Brussels.

A validation of the Agreement under question was ratified by Turkish Parliament on 23/1/2003 with the 4794 number law. Within this framework as in other countries, EEA requires that the data needed should be collected according to the EU standards, all required information on environment and other fields (industry, agriculture etc.) should be provided by Turkey during the period of adaptation to the European legislation, provision of all required information to the decision makers, provision of all information and data during the formation of politics, provision of information and data during the Environmental Impact Assessment for an acceptance of the projects prepared by the Standing member Countries of the EU as a prerequisite for getting financial support from EU, formation of a standard not attained due to different formats used by the public sectors / organizations, and private organizations related to the data on environment in Turkey, for this purpose in order to get support on the "Project on Structural Development and Communication on Environmental Information" was started by the 
"Ministry of Environment and Forests" with a participation from other organizations and sectors in this connection under a coordination of the Ministry, so as to create a national data bank for observation and reporting on environmental situation in Turkey, activation of EIONET in Turkey in order to reach on time the data of all member countries, and finally provision of data and information on environment to the public (EIONET Nedir?, 2006,).

\section{Discussion and conclusion}

Environment and environmental issues are now clear for all the world agenda. The environmental policy and issues in the past thirty and forty years have become more concrete as they stand as serious problems.

As stated in the beginning, apart from the primitive times which people dominated the nature, environmental problems really emerged in the context of Industrial Revolution and the increasing impact of rational-economic thought in the post-Industrial Revolution posed it as a concrete problem. Wherever we stand in the world, whether it be developed or underdeveloped nations, environmental problems have begun to constitute a real threat. Today it is vital and a must that we develop common projects and cooperation on a global and international scale for environmental issues, as the magnitude of the threat requires a Gestaltian approach and general solutions beyond the ideological predilections. The environment as we borrowed from our children, due to threats faced in a clear and present sense, has become a high priority item at a national, regional and international level (Ökmen, 2006).

In this regard, the EU policy perspective is essentially important for Turkey in a process of accession talks. The Environmental Jurisdiction of EU stands as an advanced framework among the ones in implementation around the world and among the administration models. As summarized in the EU legislation, arrangements on the way to a full implementation of environmental policy have been realized and developed along the principles. Henceforth, Turkey's direction for change in environmental policy-making should be perceived and implemented from the EU perspective. In the meanwhile, compared to her EU counterparts, Turkey remains at very early stages in such policy-making and implementation. In fact, such a conclusion requires a long and an arduous process to succeed for Turkey to harmonize herself with the Union's environmental policy making. There will indeed be difficulties for the local and national units in the harmonization of policies in environmental administration. The harmonization with the EU environment policy framework becomes an obligation for the member country that initially agrees to the terms of the Union in environmental administration. On the other hand, Turkey's adaptation to the EU environmental policy making will be more difficult and painful for the Turkish integration into the environmental policy-making (Yaşamış, 1995).

Turkey, besides her comparative studies with EU environmental legislations since 1987, has set its goals to change the environmental jurisdiction as a part of Customs Union. As a result, most of the Turkish jurisdiction has been harmonized with the $\mathrm{EU}$ one. The EU also ensures the full implementation of the process. The target is the implementation of Turkish environmental jurisdiction with the same approach of the EU (Egeli, 1996). According to the progress report in 2004, in terms of the horizontal jurisdiction, regulations have been found to be harmonized with the EU jurisdiction, As well as this, it was pointed out that beyond border impact and public consultation should be more emphasized. As these need to be implemented immediately, this will affect the implementation quality. The horizontal jurisdiction implementation requires a lot of effort.

Turkey has still not signed the "Kyoto Protocol". In terms of the air quality issue, steps should be taken to develop and implement air monitoring schemes and related regulations. While important measures have been taken in regard to the air quality and waste management, it still requires a lot of support to plan a national strategy to deal with waste management. Despite the legislations passed, legal harmonization has been at a minimal level. A new regulatory framework for the environmental protection, birds and habitat should also be developed. Continual extinction of habitats are also worrying. Effective implementation, in this regard, is a must. Interrelated policy fields in relation to the environmental policy should also be considered. Industrial pollution, risk management, chemical and genetically modified organism are also issues that need to be harmonized and require attention.

Henceforth Turkish obligations in terms of environmental policy making are inclusive of following: measure regarding environmental protection, identification of policies, integration scheme development and sustainable development. Integration of Environment and Forestry Ministry is a positive step in terms of administrative capacity. Such unification has not been effective though. There are still overlapping responsibilities and clash of interests between ministries and institutions. More emphasis should be laid upon local administrations within the 
local administration reform draft. In general, planning and implementation are fundamental problem. Recruitment of expertise personnel and purchase of technical equipment and implementation of framework are important steps. In the medium run, more investments need to be put. Along with such a content integration with the EU framework is a must for investment. Generally transfer to the national legal jurisdiction has remained at a minimal level coupled with weak implementation practices. Horizontal jurisdiction, air quality, waste management, water quality, industrial pollution and risk management are issues that need to be dealt in terms integration to the national jurisdiction. In this regard, institutions' capacities and coordination mechanisms be strengthened in environmental policy-making, which also requires great financial investments (Year 2004 Progress..., 2004).

European Union standards is important in this issue. While essential steps were taken along with harmonization with EU environmental standards, the list to do is not over. This indeed necessitates a mental transformation and the will to put these legal regulations into implementations. As many economic, social, cultural and politico-administrative factors are intertwined with environmental issues, we need total and holistic approaches. The approach taken by the 7th 5 year developmental program and in particular with the 8th one in a national, regional and supranational sense should be transferred into related fields regarding implementation. In this regard, policies balancing between national and other regional and supranational interests should be formed and put into implementation.

\section{References}

Bosch P., 2002, The European Environment Agency Focuses on EU-Policy in its Approach to Sustainable Development Indicators, Statistical Journal of the United Nations, 19, 4-13.

EEA Signs 2004 Update on Certain Issues of the European Environment Agency, 2004, European Environment Agency, Office of the Official Publications of the European Communities, Luxembourg.

Egeli G., 1996, Environmental Problems in the European Union and Turkey, TEF Publication, Ankara.

EIONET Nedir?, 2006, AÇA http://www.eionet.eu.int/report. net.html_08.01.2006 [10.04.2016].

Grundmann R., 2007, Climate Change and Knowledge Politics, Environmental Politics, 16(3), 414-432.

Hilty L.M., 2006, The relevance of information and communication technologies for environmental sustainability A prospective simulation study, Environmental Modelling \& Software, 21, 1618-1629.
Ökmen M., 2003, Urban, Environment and Globalization, Alfa Publishing, Istanbul.

Ökmen M., 2006, Ecology-Politics of the Integration Process: Environmental Policies in the European Union and Turkey, [in:] M. Dikkaya (ed.), Turkey on the Way to the EU: Politics of the Negotiation Process, Alfa Publications, Istanbul, 350-362.

Srebotnjak T., 2007, The role of environmental statisticians in environmental policy: the case of environmental performance, Environmental Science and Policy, 10(5), 405-418.

What is Turkey's Environmental Policy? What should it be?, 1987, TEF Publishing, Ankara.

Who is it? What are we doing? How are we doing?, 2005, European Environment Agency, Environment Agency, Office of the Official Publications of the European Communities, Luxembourg.

Williams R.J., Martinez N.D., Goldeck J., 2006, Ontologies for Ecoinformatics, Journal of Web Semantics, 4(4), 237-242.

Yaşamış F.D., 1995, The Basic Tools of Environmental Management, Imge Publishing, Ankara.

Year 2004 Progress Report on Turkey's Accession Process to the EU, 2004, SPO Publication, Ankara. 